
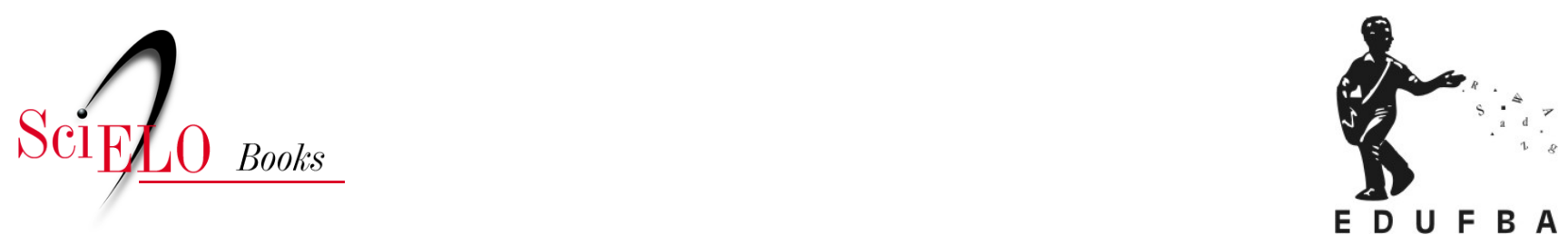

\title{
Inquérito alimentar
}

\author{
Lílian Ramos Sampaio \\ Maria da Conceição Monteiro da Silva \\ Anna Karla Carneiro Roriz \\ Venusca Rocha Leite
}

SAMPAIO, L.R., SILVA, M.C.M., RORIZ, A.K.C. and LEITE, V.R. Inquérito alimentar. In:

SAMPAIO, L.R., org. Avaliação nutricional [online]. Salvador: EDUFBA, 2012, pp. 103-112. Sala de aula collection. ISBN: 978-85-232-1874-4. https://doi.org/10.7476/9788523218744.0008.

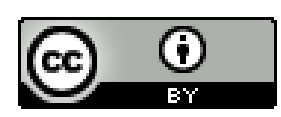

All the contents of this work, except where otherwise noted, is licensed under a Creative Commons Attribution $\underline{4.0 \text { International license. }}$

Todo o conteúdo deste trabalho, exceto quando houver ressalva, é publicado sob a licença Creative Commons Atribição 4.0.

Todo el contenido de esta obra, excepto donde se indique lo contrario, está bajo licencia de la licencia Creative Commons Reconocimento 4.0. 


\title{
Inquérito alimentar
}

\author{
Lílian Ramos Sampaio \\ Maria da Conceição Monteiro da Silva \\ Anna Karla Carneiro Roriz \\ Venusca Rocha Leite
}

\section{Introdução}

A importância dos métodos de inquérito alimentar está associada ao binômio dieta-saúde que, por sua vez, vem sendo cada vez mais estudado pela ciência. Na Avaliação Nutricional, conhecer o consumo dietético é indispensável também para estudar a relação entre alimentação e doença, investigando a participação dos nutrientes na manutenção da saúde e, consequentemente, na prevenção de morbidades; para identificar indivíduos ou grupos em risco nutricional (vigilância alimentar); para avaliar a ingestão alimentar de forma qualitativa e/ou quantitativa; para direcionar a prescrição dietética, avaliando a eficiência da intervenção; para monitorar tendências 
de ingestão; para promover a educação alimentar e para planejar e avaliar políticas públicas de alimentação e nutrição.

Dessa forma, ao escolher o método, deve-se entender a finalidade da investigação, conhecer o público alvo, os recursos disponíveis e o tipo de estudo a ser desenvolvido. Sua validade e reprodutibilidade dependem muito da habilidade do avaliador e da cooperação do entrevistado. É de extrema importância ressaltar que não há, entre todos os métodos, aquele que denominaríamos como perfeito, entretanto podemos definir o método mais adequado para cada situação.

Existem algumas definições básicas necessárias para entender e escolher o melhor método a ser aplicado. De acordo com a temporalidade, os métodos de inquérito alimentar podem ser classificados em:

1. Prospectivos: registram informações recentes e estão associados à dieta atual, ou seja, com a média do consumo alimentar em um curto período de tempo corrente. Os métodos utilizados dentro desta categoria são o recordatório 24 horas, o registro alimentar diário, a pesagem direta e o orçamento familiar;

2. Retrospectivos: colhem a informação do passado imediato ou em longo prazo e estão associados com a dieta habitual, ou seja, com um consumo padrão que o indivíduo mantém rotineiramente em um período de tempo prolongado. Para esta investigação, utilizam-se a frequência alimentar, a história dietética e os recordatórios periódicos de 24 horas. 


\section{Recordatório de 24 horas}

O recordatório de 24 horas consiste em definir e quantificar todos os alimentos (descrevendo também os horários e tipos de preparações) e bebidas consumidos nas últimas 24 horas, anteriores à entrevista - mais comumente, no dia anterior. Este deve ser um dia típico, a fim de tornar o relato do entrevistado mais próximo e real da sua dieta atual. As quantidades de alimentos e bebidas consumidos, geralmente, são estimadas em medidas caseiras e cabe ao aplicador estabelecer um elo de comunicação compreensível com o entrevistado, no propósito de colher as informações da maneira mais detalhada possível, sem induzir (Quadro 1).

\begin{tabular}{|ll|}
\hline Vantagens & Limitações \\
\hline Baixo custo, fácil e rápida apli- & Depende da memória do entrevistado \\
cação & Requer treinamento do investigador \\
Quando realizado em série, for- & para evitar indução \\
nece estimativa da ingestão usual & A ingestão prévia nas últimas 24 horas \\
do indivíduo & pode ter sido atípica \\
$\begin{array}{l}\text { Pode ser aplicado em diferentes } \\
\text { faixas etárias e em analfabetos }\end{array}$ & $\begin{array}{l}\text { Não reflete diferenças entre a ingestão } \\
\text { de dias da semana e fim de semana. }\end{array}$ \\
$\begin{array}{l}\text { Pode ser utilizado para estimar a } \\
\text { ingestão energética e de macro- } \\
\text { nutrientes. }\end{array}$ & $\begin{array}{l}\text { Dificuldade em estimar o tamanho } \\
\text { das porções }\end{array}$ \\
Não altera a dieta usual & $\begin{array}{l}\text { Bebidas e lanches tendem a ser omi- } \\
\text { tidos }\end{array}$ \\
Descreve hábitos culturais & \\
\hline
\end{tabular}

Quadro 1 - Vantagens e limitações do recordatório de 24 horas

Fonte: Kamimura e colaboradores (2005). 


\section{Registro Alimentar}

Neste método, o indivíduo registra detalhadamente todos os alimentos e bebidas consumidos em um determinado espaço de tempo, descrevendo tipo de preparações, ingredientes, marca do alimento, porção em medidas caseiras e horário das refeições. Preconiza-se o registro de 3 a 7 dias para que seja possível avaliar a ingestão habitual, sem induzir modificações no hábito alimentar (Quadro 2). A aplicação deve ser realizada em dias alternados, incluindo, se possível, um dia do fim de semana. Essa metodologia proporciona uma melhor estimativa da ingestão alimentar habitual do indivíduo.

Uma variação deste método é o registro alimentar por peso dos alimentos, em que o indivíduo deve fazer uso de balança, tornando a avaliação de consumo mais precisa e exata quanto às porções ingeridas. Neste método, todos os alimentos, bebidas e sobras devem ser pesados com seus respectivos pesos registrados. Suas limitações incluem o custo elevado pela aquisição da balança, bem como sua calibração, além de uma possível tendência em modificar os hábitos alimentares simples. Apesar de ser mais preciso que o registro alimentar estimado, a aplicação desta variação requer investimento, treinamento e colaboração do cliente, o que torna mais rara sua utilização na prática. 


\begin{tabular}{|ll|}
\hline Vantagens & Limitações \\
\hline Não depende da memória & Pode interferir no padrão alimentar \\
$\begin{array}{l}\text { Proporciona maior acurácia e preci- } \\
\text { são quantitativa dos alimentos }\end{array}$ & Requer tempo \\
$\begin{array}{l}\text { Identifica tipos de alimentos, } \\
\text { preparações e intervalos entre as }\end{array}$ & escrever o indivíduo saiba ler e \\
refeições & $\begin{array}{l}\text { Dificuldade para estimar as quanti- } \\
\text { dades ingeridas }\end{array}$ \\
\hline
\end{tabular}

Quadro 2 - Vantagens e limitações do registro alimentar por estimativa Fonte: Kamimura e colaboradores (2005).

\section{História Alimentar ou História Dietética}

Consiste em uma ampla entrevista que objetiva descrever a ingestão dos alimentos do ponto de vista qualitativo e quantitativo, coletando informações referentes aos hábitos alimentares atuais e passados, tratamento dietético anterior; modificações nas condições de vida e na ingestão alimentar, além de preferências, intolerâncias e aversões alimentares. Além destes aspectos, são também contemplados fatores relacionados ao estilo de vida e ao uso de medicamentos e/ou suplementos. A entrevista pode incluir o recordatório de 24 horas, o registro alimentar (se possível) e/ou o questionário de frequência alimentar. É muito utilizada em atendimentos de primeira consulta (Quadro 3). 


\begin{tabular}{|c|c|}
\hline Vantagens & Limitações \\
\hline \multirow{2}{*}{$\begin{array}{l}\text { Leva em consideração as variações } \\
\text { sazonais }\end{array}$} & Alto custo \\
\hline & Requer um nutricionista altamente \\
\hline \multirow{2}{*}{$\begin{array}{l}\text { Fornece uma completa e detalhada } \\
\text { descrição quantitativa e qualitativa } \\
\text { na ingestão alimentar }\end{array}$} & treinado \\
\hline & $\begin{array}{l}\text { Depende da memória do entrevis- } \\
\text { tado }\end{array}$ \\
\hline Elimina variações do dia-a-dia & Tempo de administração longo \\
\hline $\begin{array}{l}\text { Fornece uma boa descrição da in- } \\
\text { gestão usual }\end{array}$ & $\begin{array}{l}\text { Dificuldade de padronização a } \\
\text { informação na abordagem coletiva }\end{array}$ \\
\hline \multicolumn{2}{|l|}{ Informa o hábito alimentar } \\
\hline $\begin{array}{l}\text { Importante para estudo da relação } \\
\text { entre o alimento e doença/proble- } \\
\text { mas nutricionais na clínica }\end{array}$ & \\
\hline
\end{tabular}

Quadro 3 - Vantagens e limitações da história alimentar

Fonte: Kamimura e colaboradores (2005).

\section{Questionário de Frequência Alimentar}

Este método estima a ingestão habitual de alimentos ou nutrientes específicos, com base em uma lista contendo diferentes alimentos e suas respectivas frequências de consumo por dia, semana, mês ou ano. Assim, o padrão alimentar pode ser avaliado qualitativamente e semi-quantitativamente, uma vez que, neste último, há a padronização prévia do tamanho da porção de cada alimento/preparação, de acordo com o hábito do grupo ou população que está sendo investigado (Quadro 4). Através da elaboração prévia de um questionário direcionado (lista de alimentos e/ou preparações), é possível avaliar o consumo e as necessidades alimentares específicas de diferentes populações. 


\begin{tabular}{|c|c|}
\hline Vantagens & Limitações \\
\hline $\begin{array}{l}\text { Baixo custo, simples administra- } \\
\text { ção, não requerendo tanta especia- } \\
\text { lização do entrevistador }\end{array}$ & $\begin{array}{l}\text { Impossibilidade em saber as cir- } \\
\text { cunstâncias em que o alimento foi } \\
\text { consumido }\end{array}$ \\
\hline Não altera o padrão de consumo & Quantificação pouco exata \\
\hline Estima a ingestão habitual & Pode haver subestimação por não \\
\hline $\begin{array}{l}\text { Pode descrever padrões de inges- } \\
\text { tão alimentar }\end{array}$ & $\begin{array}{l}\text { contemplar todos os alimentos con- } \\
\text { sumidos pelo indivíduo }\end{array}$ \\
\hline $\begin{array}{l}\text { Utilidade nas pesquisas epidemio- } \\
\text { lógicas }\end{array}$ & $\begin{array}{l}\text { Dificuldade da análise sem uso de } \\
\text { computadores e programas especiais }\end{array}$ \\
\hline $\begin{array}{l}\text { Pode ser utilizado para associar } \\
\text { nutrientes específicos às patologias } \\
\text { e necessidades fisiológicas. }\end{array}$ & $\begin{array}{l}\text { Necessidade em elaborar questioná- } \\
\text { rios direcionados. Listas pequenas } \\
\text { ( }<50 \text { itens) podem subestimar a } \\
\text { ingestão e as grandes ( }>150 \text { itens) }\end{array}$ \\
\hline Pode ser autoaplicável & podem gerar fadiga. \\
\hline Gera resultados padronizados & $\begin{array}{l}\text { Depende da memória do entrevista- } \\
\text { do e, caso seja auto-aplicado, depen- } \\
\text { derá do grau de escolaridade. }\end{array}$ \\
\hline
\end{tabular}

Quadro 4 - Vantagens e limitações da frequência alimentar Fonte: Kamimura e colaboradores (2005).

\section{Fontes de Erro na Avaliação do Consumo Alimentar}

As etapas de avaliação do consumo alimentar envolvem a coleta de dados sobre a dieta, a transformação das medidas caseiras em gramas, o cálculo do teor dos nutrientes nos alimentos e a análise da ingestão.

As fontes de erro mais frequentes neste processo de avaliação estão relacionadas ao entrevistador, ao entrevistado e ao instrumento de coleta, e interferem na precisão da avaliação do consumo dietético, o que compromete a qualidade do resultado. 
Entre as fontes mais comuns, destacam-se aquelas referentes à confiabilidade da informação (dependente da cooperação do entrevistado), falta de habilidade do entrevistador (perguntas facilitadas que terminam por induzir o entrevistado), erros inerentes à própria técnica ou da tabela de composição dos alimentos e padrões de referência. Outros como o processamento e a cocção dos alimentos podem favorecer a perda de micronutrientes, interferindo na sua biodisponibilidade, ocasionando um viés no resultado da avaliação.

Para minimizar esses erros e melhorar a acurácia das estimativas do consumo alimentar, é necessário avaliar qual método se aplica a uma determinada situação, visto que não há um método ideal ou que seja padrão-ouro, pois todos apresentam alguma(s) fonte(s) de erro(s). Sendo assim, deve-se investir no aperfeiçoamento dos métodos já existentes, através da elaboração de questionários padronizados e de lista de alimentos, bem como na utilização de técnicas estatísticas sofisticadas de análise.

O preenchimento do instrumento de coleta deve ser realizado cuidadosamente, atentando para o tamanho das porções e para o uso de utensílios. Além disso, torna-se indispensável o treinamento de entrevistadores para garantir habilidade em coletar os dados com mais precisão.

\section{Considerações Finais}

Em que pese as tentativas de aperfeiçoamento dos métodos de coleta de consumo alimentar, no sentido da obtenção de dados com melhor precisão e acurácia, os métodos citados acima (recordatório de 24 horas e frequência alimentar) são os mais utilizados na prática clinica e epidemiológica, pelas vantagens já referidas. 
Os cuidados com treinamento, padronização e validação são importantes para a qualidade das informações necessárias à determinação do padrão alimentar de indivíduos e grupos populacionais, assim como da explicação do diagnóstico nutricional e identificação de grupos de risco. Salienta-se, também, a importância do conhecimento do perfil alimentar na tomada de decisão para definição de políticas públicas. No Brasil, vários estudos têm sido realizados para conhecer o padrão alimentar do povo brasileiro. Na década de 70, mais precisamente de 1974 a 1975, foi realizada a primeira pesquisa nacional sobre consumo familiar pelo IBGE e o Instituto Nacional de Alimentação e Nutrição (INAN), intitulado Estudo Nacional de Despesas familiares (ENDEF). Neste estudo, foi utilizado o método de peso e medidas ou pesada direta durante 7 dias, considerado, na época, pela FAO, como o método de maior confiabilidade e exatidão. A partir de então, pelo alto custo e complexidade logística do método de pesada direta em estudos populacionais, tem-se estudado a mudança no perfil alimentar da população brasileira por meio do método do orçamento familiar.

Deste modo, a pesquisa de orçamento familiar (POF's), realizada pela primeira vez em 1961/1962, nas regiões Sul, Sudeste e Nordeste, pela Fundação Getulio Vargas (FGV), é retomada em 1987/1988, sendo realizada desta vez pelo IBGE nas áreas metropolitanas de Porto Alegre, Curitiba, São Paulo, Rio de Janeiro, Belo Horizonte, Salvador, Recife, Fortaleza, Belém, Goiânia e Brasília, acontecendo, assim, em 1996/1997 (IBGE). Já em 2002/2003, a POF também foi realizada pelo IBGE, nas áreas rurais e urbanas de todo o território nacional. 


\section{Referências}

FISBERG, R. M. et al. Inquéritos alimentares: métodos e bases científicos. São Paulo: Manole, 2005.

HOLANDA, L. B.; BARROS FILHO, A. A. Métodos aplicados em inquéritos alimentares. Revista Paulista de Pediatria, São Paulo, v. 24, n. 1, mar. 2006.

KAMIMURA, M. A. et al. Avaliação nutricional. In: CUPPARI, L.; SCHOR, N. Guias de Medicina ambulatorial e hospitalar: nutrição clínica no adulto 2. ed. Barueri: Manole, 2005. p. 89-127.

MAHAN, L K.; ESCOTT- STUMP, S. Krause: alimentos, nutrição e dietoterapia. 11. ed. São Paulo: Roca, 2005. 